\title{
UNA "PRINCESA TRISTE, QUE HA PERDIDO LA RISA, QUE HA PERDIDO EL COLOR". CUERPO Y VIOLENCIA EN CIERRA LOS OJOS, PRINCESA DE JOSÉ ALEJANDRO CASTAÑO ${ }^{1}$
}

\author{
A "sad princess, who has lost laughter, who has lost colour. \\ Body and violence in Cierra los ojos, princesa by José Alejandro Castaño \\ Daniuska González González*
}

\begin{abstract}
RESUMEN
El presente artículo pretende analizar la construcción de un cuerpo de la violencia en la novela Cierra los ojos, princesa (2012) de José Alejandro Castaño (Medellín, 1972). Para esto, se recurrirá a una lectura de las múltiples tipologías de cuerpos que se elaboran en esta narrativa, para lo cual se contará con autores teóricos como David Le Breton, Jean Luc Nancy y Yuber Rojas Ariza. El aporte de este texto radicaría en entender un periodo de la historia colombiana mediante la incorporación a la literatura de una corporalidad necro-lógica de la violencia contemporánea.

Palabras clave: José Alejandro Castaño, Literatura Hispanoamericana, Crítica Literaria, Siglo XXI.
\end{abstract}

* Departamento de Literatura, Facultad de Humanidades/Centro de Estudios Avanzados (CEA), Universidad de Playa Ancha. Valparaíso, Chile. Correo electrónico: daniuska.gonzalez@upla.cl

Agradezco el diálogo teórico con el colega Dr. Héctor Andrés Ferrada.

${ }^{1}$ Dentro del proyecto "Los personajes fatales. Sujetos, personajes y derivas en relatos de vida y en la narrativa de los chilenos Roberto Bolaño, Alejandro Zambra y Diego Zúñiga y del colombiano Juan Gabriel Vásquez" del Centro de Estudios Avanzados (CEA) de la Universidad de Playa Ancha, el presente artículo forma parte de la aproximación a la figura de Pablo Escobar Gaviria y su representación en el relato de memorias y la narrativa.

Artículo recibido el 01 de junio de 2018. Aceptado el 06 de agosto de 2018. 


\begin{abstract}
The aim of this article is to analise the construction of a body of violence in the novel Cierra los ojos, princesa written by José Alejandro Castaño (Medellín, 1972). To do this, there will be a reading of the multiple types of bodies that are elaborated in this narrative following the guidance of theoretical authors such as David Le Breton, Jean Luc Nancy y Yuber Rojas Ariza. This text would contribute to understand a period of Colombian history by way of the incorporation of a necro-logic corporality of contemporary violence into literature.
\end{abstract}

Keywords: José Alejandro Castaño, Hispanoamerican Literature, Literary Criticism, XXI century.

"Eso es el pasado: un relato, un relato construido sobre otro relato, un artificio de verbos y sustantivos donde acaso podamos apresar el dolor de los hombres, su miedo a la muerte y su afán de vivir".

Juan Gabriel Vásquez, La forma de las ruinas.

\title{
1. Una princesa que "no ríe", que "no siente"2. A manera de preámbulo
}

La novela Cierra los ojos, princesa $^{3}$ de José Alejandro Castaño (Medellín, 1972) parte de múltiples voces alrededor de una niña, Manuela Escobar Henao ${ }^{4}$, hija del narcotraficante colombiano Pablo Escobar Gaviria. El autor abre compuertas hacia ella relatando la vida de esta "princesa" depresiva

\footnotetext{
${ }^{2}$ Tanto el título del artículo como de los acápites citan versos del poema "Sonatina" del nicaragüense Rubén Darío, esto con el propósito de jugar creativamente con el título de la novela.

${ }^{3}$ Después de una exhaustiva búsqueda con el objetivo de levantar el Estado del Arte, no se encontraron artículos académicos sobre esta novela ni sobre su autor. Sin embargo, se resaltan tres notas y una entrevista que se aproximan al libro: "Cierra los ojos, princesa, José Alejandro Castaño" de Daniel Ferreira (http:// blogs.elespectador.com/cultura/en-contra/cierra-los-ojos-princesa 8 de marzo de 2013); "Manuela, la hija del Patrón, enfrenta su propio drama" de KienyKe (https://www.kienyke.com/historias/la-hija-delpatron 24 de septiembre de 2012); "José Alejandro Castaño: el libro de la hija de Pablo Escobar" (S/A. http://www.jetset.com.co/edicion-impresa/temas-revista-jetset/articulo/jose-alejandro-castano-libro-hijapablo-escobar/62296 5 de octubre de 2012); y "El escritor y periodista José Alejandro Castaño, habla de su nuevo libro 'Cierra los ojos, princesa'” (http://www.wradio.com.co/escucha/archivo_de_audio/elescritor-y-periodista-jose-alejandro-castano-habla-de-su-nuevo-libro-cierra-los-ojos-princesa/20121101/ oir/1789126.aspx 1 de noviembre de 2012).

${ }^{4} \mathrm{Al}$ respecto, resultan fructíferas las palabras del propio autor en una entrevista de la revista colombiana Jetset:

"-Hablé con la madre y el hermano. Nunca tuve contacto con ella. En realidad, esta es una novela que se desprende de las conversaciones con cerca de cincuenta personas vinculadas a Escobar. En Panamá, me reuní con una de sus excriadas. También hablé con otra mujer que le cuidó a la hija. Además, viajé
} 
Una "princesa triste, que ha perdido la risa, que ha perdido el color".

Cuerpo y violencia en Cierra los ojos, princesa de José Alejandro Castaño.

y curiosa, que llevaba "una corona de oro blanco con diamantes y un peine para fijarla en el cabello" (Castaño, 2012, p. 28), costoso regalo del padre, y de la que todos decían que "era la reina" (28). Además, en un espacio paralelo a este relato central aparece una fábula con el tradicional comienzo "Había una vez..." (13), en la cual se arma el vínculo afectivo, sin sobresaltos, entre la princesa y el rey. Es decir, la narración se estructura en dos niveles: el principal con las voces cercanas al jefe del Cártel de Medellín; y otro, secundario, con esta pequeña fábula que adorna la crudeza de la realidad hasta donde resulta posible y que se vale de este género que se apega como ningún otro a la ficcionalización: "Y el rey era tan astuto que una vez logró que un cocodrilo se mordiera la cola" (35).

Para escribir esta novela, Castaño residió en la casa bonaerense de María Victoria Henao, la viuda de Escobar, y sus dos hijos, Juan Pablo y Manuela, de ahí que el texto escudriñe en los detalles domésticos de la dinámica familiar, así como que sostenga una mirada acuciosa acerca de acontecimientos a los cuales el autor tuvo acceso a través de fotografías y relatos contados por estas fuentes de primera mano. No está demás acotar que la vida de Manuela, la princesa de la ficción, se cruza con la vida íntima del Capo y con la vida pública de Colombia en un periodo cruento y desgastante.

Esta novela se separa de la narrativa ${ }^{5}$ explícita sobre el contexto de la guerra de los cárteles colombianos (comienzo de la década del 70-mediados de los años 90), como La virgen de los sicarios (1994) de Fernando Vallejo y Rosario Tijeras (1999) de Jorge Franco, citando solo dos títulos, la cual quedó superada cuando otros discursos ficcionales buscaron una comprensión de este pasado, aún reciente y con secuelas visibles, mediante un abordaje perfilado,

a Buenos Aires, donde me atendió uno de los choferes que él tenía en Medellín. [...] —Es un relato novelado. Como dice Vargas Llosa: "La literatura es un streeptease a la inversa. Es decir, una realidad desnuda que se va cubriendo". En este libro hay una cantidad de verdades ocultas por la fantasía. [...] - Este libro es el lado B de un disco rayado de Escobar. Es la otra historia a partir de una niña que pierde a su padre, que para ella era un rey todopoderoso. Le hacía aparecer todo lo que ella quería." En http://www.jetset.com.co/edicion-impresa/temas-revista-jetset/articulo/jose-alejandro-castano-libro-hijapablo-escobar/62296 (02/02/2018).

${ }^{5}$ Aunque se ha trabajado exhaustivamente, se acota que la narcoliteratura (para alguna crítica cabe el epíteto de "sicaresca" o "novela del sicariato" debido a la problematización de la figura del sicario; para otra formaría parte de la denominada "novela de la violencia", definición más abarcadora) hizo una estética del narcotráfico y su trasvasamiento hacia la política, la economía y, obviamente, la sociedad; y de la violencia de los cárteles (con su maquinaria de sicarios, secuestros y muertes y su imaginario topográfico incrustado en ciudades como Medellín y sus comunas) y la devuelta por el gobierno, la guerrilla y el paramilitarismo -observando, por supuesto, sus contradicciones y sus acuerdos, por ejemplo, el vínculo entre el Cartel de Medellín y el movimiento guerrillero M-19-, lo cual engendró una representación ficcional importante, como la pionera La virgen de los sicarios (1994) de Fernando Vallejo, citada en el texto, y Angosta (2003) de Héctor Abad Faciolince. 
de aristas más individuales y complejas que articulan, por ejemplo, la ruina y la apatía del sujeto frente al "legado" de la violencia (El ruido de las cosas al caer [2011] y La forma de las ruinas [2015] de Juan Gabriel Vásquez), la obturación de la historia a través de dislocaciones y ocultamientos (Tríptico de la infamia [2014] de Pablo Montoya) o algunos registros psicológicos como el encierro en El mundo de afuera ${ }^{6}$ (2014) del propio Franco.

En este escenario narrativo irrumpe Castaño, polémico periodista de investigación, Premio Casa de las Américas 2003 en Literatura Testimonial, con una propuesta que hurga tanto en el periodo de terror de Escobar como posteriormente, leyéndolos con saltos cronológicos y desde múltiples cuerpos que relatan la intimidad de la hija. Al autor no le preocupa la historiografía, sus acontecimientos fechados, sino ejecutar un trabajo arqueológico con el detalle íntimo, privado, con lo cual pretende dar al traste con "verdades" asentadas tanto en el tiempo de enfrentamiento entre los cárteles como después.

De esta manera, la novela instala una pregunta: ¿Cómo contar a partir de un borramiento, de una clausura identitaria y de la violencia que arrasó con la mayoría de sus actores y con muchas de sus víctimas? ¿Cómo crear una figura o un dispositivo que se haga relato, que hable? Después del asesinato del capo, su viuda y sus dos hijos cambiaron de identidad y salieron de Colombia hacia un destino desconocido, que solo se descubrió dos años después de residir en él, la ciudad de Buenos Aires. Con estas interrogantes se produce el acople con las voces de los testigos como restos de una catástrofe, la de la violencia, que merecen atención porque completan un proceso histórico complejo.

De ahí que el autor recurra a la noción de cuerpo como una subjetividad que adopta múltiples formas para manifestarse. Al respecto, la cita de Juan Francisco García et al. soporta lo anterior y sirve como preámbulo a los autores Jean Luc Nancy y David Le Breton, quienes, junto al investigador colombiano Yuber Rojas Ariza, conformarán la línea teórica de análisis del presente artículo: "el cuerpo es, se da, en tanto 'expresiones' [...] El cuerpo es en sí mismo su 'estar en el mundo'. [...]. El cuerpo es expresión, es un estar en el mundo expresivo que abre lo otro y que densifica al propio hombre" (2014: 8). Esta subjetividad permite leer la violencia ${ }^{7}$ como un enorme pliego corporal, el resultado final de la aglomeración de cuerpos diferentes, corporalidades depresivas, exhumadas, temerosas, abyectas, enfermas y destrozadas por la muerte.

\footnotetext{
${ }^{6}$ Tanto la novela de Castaño como la de Franco, Premio Alfaguara de Novela 2014, se apropian de la fábula como formato para leer el tiempo de la violencia en Colombia durante la guerra de los cárteles y posteriormente.

${ }^{7}$ Este concepto es atravesado por múltiples disciplinas, contextos y discusiones teóricas, por eso la amplitud de miradas críticas y polisémicas sobre/a partir de ella. Acotando para este artículo que se enfoca
} 
Una "princesa triste, que ha perdido la risa, que ha perdido el color".

Cuerpo y violencia en Cierra los ojos, princesa de José Alejandro Castaño.

Aunque Castaño pudo recurrir a otra categoría, por ejemplo, la de sujeto, como hace Vásquez, el cuerpo le propició un molde más dúctil, un recipiente con más texturas explícitas para que la violencia se sujetara y adquiriera volumen a través de un sentido necro-lógico, como se analizará más adelante con el planteamiento de Rojas Ariza, pues este cuerpo de la violencia, deriva última de múltiples y concatenados cuerpos individuales, "se encuentra atado al Régimen disciplinario de la vida moderna; una lógica al servicio de la muerte donde el conocimiento humano resulta determinante" (Rojas Ariza, 2016, p. 748).

Como señaló Nancy, interesa el cuerpo que "puede volverse hablante, pensante, soñante, imaginante [que] Todo el tiempo siente algo" (2010, p. 15), y que, como su tesitura final, dará cuenta de la violencia, esta también como cuerpo, en una época particular de la historia colombiana. Cuerpo en tanto subjetividad que constantemente se actualiza, emerge o desaparece, en este caso como subjetividad de la violencia incesante.

El cuerpo en la novela se pensará no como una unidad compacta de lo vivo o, en su defecto, de la materia muerta, sino como una pluralidad entretejida por múltiples organismos que construyen otro mayor: a través de la condición de varios cuerpos (enfermo, culpable, temeroso, abyecto, anulado, entre otros), se llegará a uno mayúsculo como consecuencia: el de la violencia, para entender un momento de la historia colombiana (el de los cárteles de la droga y la guerra que impusieron) a través del cuerpo, precisamente el dispositivo que más sufrió y sobre el que se encarnó con más saña la tecnología del terror.

El autor problematiza el cuerpo hasta el límite de hacerlo testigo de acontecimientos, creando un emplazamiento corpóreo mayor, una materialidad compacta. Estas formas corporales, al trabajarse individualmente, posibilitan su agrupamiento después en uno de los espacios más problemáticos de la contemporaneidad, el de la violencia. "Desde las técnicas del cuerpo a las expresiones de la afectividad, desde las percepciones sensoriales a las inscripciones tegumentarias, [...], el cuerpo es materia inagotable de prácticas sociales, representaciones, imaginarios" (Le Breton, 2005, p. 1718). Tomando como norte esta cita de Le Breton, se verán los cuerpos de la novela como materias dúctiles, "representaciones, imaginarios", células que se entretejen hasta alcanzar una instancia corporal mayor que instaura la discursividad de la violencia.

en Colombia, se precisará a partir de un autor de ese país, que la visualiza como práctica "de imponer, intimidar y persuadir a [...] grupos y al Estado" (Salazar, 2000, p. 175). Para complementar lo anterior, también en el sentido explorado por Slavoj Zizěk en Sobre la violencia. Seis reflexiones marginales (2009): la violencia como representación simbólica "encarnada en el lenguaje y sus formas" (10), con su sistema de signos que instala un imaginario potente. 


\section{Cuerpos minúsculos, presos "en sus oros, [...] en sus tules"}

Cuerpos masacrados, objetos de/para la muerte... Si el lector quisiera permanecer en la superficie de la novela sería imposible debido al numeroso arrojo de cuerpos como voces que gritan sus estados de conmoción y recuerdos. En esta dirección no se puede olvidar, como señaló Le Breton (2002), que

Las representaciones del cuerpo y los saberes acerca del cuerpo son tributarios de un estado social, de una visión de mundo y, dentro de esta última, de una definición de la persona. El cuerpo es una construcción simbólica, no una realidad en sí mismo (13).

A partir de esta cita, se puede reconocer un primer cuerpo, perteneciente a Manuela, que instaura un saber sobre la depresión. Como cuerpo depresivo sometido a la terapia sicológica, es un cuerpo hablante. Internado en una clínica, parece responder, en primera instancia, al desconocimiento sobre la historia del padre, a su comprensión racional, esto tomando en cuenta que la novela se inicia en su infancia; sin embargo, luego sorprende ya que, mediante breves puntadas regadas al azar, se encuentra lúcidamente al tanto del pasado y de su identidad. En una segunda interpretación, se trataría de un artilugio para controlar la ira y la soledad frente al mundo, que la han convertido en un cuerpo animal acorralado. Esta corporalidad depresiva proviene del trauma y puede ser una metáfora del devenir herido de la sociedad durante y posterior a la narcoguerra, una enorme materialidad corporal atacada y maltrecha.

Como una mortaja de palidez y silencio, este cuerpo ni siquiera siente el "graznido de [los] pájaros" (Castaño, 2012, p. 195), es un cuerpo entre sombras (195), con pulsiones tanáticas, capaz de arrancar con sus manos la vida de un pequeño gato: "sintió el esqueleto de la garganta, apretó los puños [...]. Morite ya, le dijo sin dejar de apretar" (195); y que llega hasta el encierro en el siquiátrico, "medicad[o], sonámbul[o], con una tristeza más grande que ella porque el mundo que vos le ofreciste ya nadie más se lo puede dar" (214).

Este cuerpo depresivo se ensancha para hilvanar un continuum de historias que median entre él y el mundo, y se observará a sí mismo atravesado por la majestuosidad de su investidura imaginaria de princesa. A veces se apropia de la gestualidad de la desobediencia y va nombrando su mundo, como si señalara el principio de la vida: "yo les ponía nombres a las vacas" (Castaño, 2012, p. 146), con lo cual este cuerpo habla, sueña, imagina (Nancy, 2010), como cuando visita la colección de carros antiguos del padre y se reconoce en su propia ficción: "En las tardes, $[\ldots]$ recorría el mundo en ellos. Y el tiempo 
Una "princesa triste, que ha perdido la risa, que ha perdido el color".

le alcanzaba. Iba a la selva, al Polo Norte, [...], a un baile con Cenicienta, y se ponía tacones y su corona, y se perfumaba el cabello" (Castaño, 2012, p. 29).

Así mismo, se narra frente al psiquiatra, con lo cual realiza una operación ambivalente de desestructurarse y juntarse a través de la palabra. Cuerpo obturado que, a pesar de armarse en el acto de evocar -"Digo cosas [...] cuando estoy con ella [la psicóloga]. Se supone que eso me ayuda" (Castaño, 2012, p. 146)-, percibe que "Algo en los recuerdos huele mal" (146) y esto le impide deslindarse de su depresión.

Este cuerpo depresivo queda expuesto frente a un segundo cuerpo, el exhumado, con el cual comparte el "sol negro" de la muerte. Recluido en la clínica psiquiátrica, el primero observa el ritual del desentierro del segundo:

Había hombres con palas que cavaban una tumba [...] Sacaron los huesos. [...] entregaron la calavera, astillas del ataúd desbaratado en las cuencas de los ojos, los dientes sonreían. El sobrino la exhibió sin pudor frente a la cámara, explicó el balazo que lo mató, asomó un dedo por el orificio de la bala, $[\ldots]$. Luego le arrancaron los dientes a la calavera, [...]. La princesa vio las imágenes en el comedor de una clínica, una de tantas, el televisor adosado a la pared (Castaño, 2012, p. 218).

Retomando a Nancy, estos cuerpos se "abisman", se "inundan" y se "distienden". Al mismo tiempo que se exponen, se anulan, uno por el abatimiento, otro por la expiración. Suprimidos de la circulación social, se conectan a través de una mirada que sutura el pasado con el presente, una mirada que, como un uróboro, entrelaza lo concluido - han transcurrido trece años desde la muerte de Escobar y su guerra con el Cártel de Cali y el gobierno- con el desarrollo de una puesta en escena de "normalidad" como forma de vida del cuerpo depresivo.

Además, estos cuerpos se trenzan con un tercero, un cuerpo del miedo y también de la abyección, que semeja una narrativa en sí mismo porque posee información de primera mano: aquel que pertenece a María Victoria Henao, la viuda de Escobar y madre de Manuela.

Al respecto, en la novela destacan dos cuerpos femeninos, el de Manuela y el de su progenitora. Más allá de las características que se han trabajado, no puede soslayarse su tratamiento a partir de circunstancias de minusvalía, es decir, rezuman miedo y desdicha y están en crisis. A simple vista, esto se conecta con el dominio patriarcal, que lo instala en una fase menor de participación, confinado: el constructo femenino como gestor y depositario a un mismo tiempo de condiciones afectivas sentimentales, destinadas solo a una circulación privada, intrafamiliar. Sin embargo, siguiendo el trazado de uno de 
los autores teóricos centrales de este artículo, Le Breton, se prefiere vincular esta representación con la de un "cuerpo sensible" en tanto "dimensión de la corporalidad humana más allá de su mera presencia orgánica y física" (Fritz en Le Breton, 2010, p. 9). Para el sociólogo francés, el cuerpo se vale de técnicas para expresarse en tanto afectividad, por esta razón el llanto, el gesto depresivo o el temor se inscriben como tecnologías para presentar "una sensibilidad propia" (Le Breton, 2010, p. 18), que no tiene que ver con minusvalías sino, al contrario, con un ejercicio de posicionamiento y con una potente "comprensión del mundo [como un] asunto del cuerpo" (18). Lo que pudiera parecer disminución se revierte, estas corporalidades no temen exponerse, necesitan comunicarse y tender puentes, decir y decirse sobre el camino complejo que han atravesado, como si se armaran lúcidamente a partir de ser cuerpos-voces, ser cuerpos-narraciones.

Entonces, en el exilio, el cuerpo materno se confronta desde dos perspectivas: una que sucumbe al miedo: "Ahora me sorprendo de lo que fui capaz de soportar [...] obliga[d]a a caminar encorvada" (Castaño, 2012, p. 176), y otra que siente la liberación mas continúa prisionera: "después de tantos años de vértigo, de mareo, de náuseas, la quietud se me hacía insoportable" (176). Su corporalidad cohesiona la experiencia traumática y la revive, como si fuera un proceso de rumia, "lloraba sin motivo, lidiaba con algo, no sabía con qué" (176), pero en el que urge contar: "una historia equivalente, también dolorosa y brutal, podía compensar la verdad verdadera" (172).

Temerosa, al borde del colapso, se encarga de dejar un resquicio para asomarse al pasado y para que se puedan rastrear fragmentos de lo sucedido, inherentes a una subjetividad a la defensiva, que se ha ido deslavando no obstante su obstinada intencionalidad de historiar: "Era como caminar sobre la Luna $[\ldots]$ el cerebro insiste en sentir lo que ya no siente" (176). En definitiva, se valida como un cuerpo-voz.

Al mismo tiempo, es un cuerpo abyecto redimiéndose a través de la limpieza y del contacto con la suciedad, que se reconoce culpable y, por esto, se condena a una cercanía con la hediondez:

Esto es un rastro de inmundicia seca, hay que remojarla, luego estregarla, es el obsequio de un grupo de policías que me hacen un favor al permitirme limpiar sus inodoros. [...]. Por eso limpiar las inmundicias de otros fue como limpiar las mías. Y fue sanador (Castaño, 2012, p. 214).

Por una parte, este cuerpo soporta el miedo y lo grita, por otra, se sumerge en lo abyecto, dando paso a "[lo] que perturba [...], [a] lo ambiguo, 
Una "princesa triste, que ha perdido la risa, que ha perdido el color".

Cuerpo y violencia en Cierra los ojos, princesa de José Alejandro Castaño.

[a] lo mixto" (Kristeva, 1989, p. 11) y potenciando la traza para ese otro cuerpo mayor, obsceno, que será el cuerpo de la violencia, como se abordará.

Al lado de estos cuerpos, hay otro que merece atención: un cuerpo enfermo, al borde de la muerte, que solo justifica su presencia porque se ha transformado en un cuerpo en negociación. Cuando llegaron a Buenos Aires, la viuda y sus dos hijos se hospedaron en un hotel en ruinas; luego de un tiempo, el dueño enfermó y decidió vendérselo a María Victoria. En el hospital, se produce un diálogo cuyo epicentro se organiza en torno a este cuerpo devastado:

Estaba conectado a una bolsa de suero y a una manguera que le soplaba oxígeno por la nariz. Se veía aún más flaco y más calvo, con los pelos de la barba encanecidos, la boca reseca, pero no dejó de hablar.

$[\ldots]$

Una enfermera entró a la habitación y mezcló el medicamento del dolor en la bolsa de suero. Antes de salir miró a la viuda y le sonrió compasiva, dándole el pésame de manera anticipada (Castaño, 2012, pp. 186-187).

A esta corporalidad solo le queda hablar, ir hacia el pasado a través del recuerdo y convertirse, como los cuerpos de Manuela y su madre, en un cuerpo de palabras. Entre su condición moribunda y lo que representa como moneda de canje, únicamente posee su voz agrietada por la duda y la soledad, ya que para él "El pasado puede hundirse en el océano [...], igual que se hunde un transatlántico, así como se hundió el Titanic, [...] el mar es más grande que el pasado más inmenso" (Castaño, 2012, pp. 185-186). En él, que se retomará en el siguiente acápite, se puede ver parte del sentido necro-lógico del cuerpo (Rojas Ariza, 2016), la "lógica al servicio de la muerte donde el conocimiento humano resulta determinante" (748).

Por último, un cuerpo destrozado y otro suicidado. El primero pertenece a Tuerquita, un hombre humilde, payaso en las fiestas de la princesa, y a quien el Patrón convence con engaños para que aborde un avión ${ }^{8}$ y cumpla un encargo:

¿Usted alguna vez ha montado en avión? [...] cuando esté sentado $[\ldots]$ le van a entregar una cajita, es un medidor de distancia, y a los cinco minutos exactos después de despegar, a los cinco minutos exactos, usted lo activa: es cosa de apretar un botón y listo. Con ese trabajo lo voy a sacar de ese oficio de payaso (Castaño, 2012, p. 68).

\footnotetext{
${ }^{8}$ Este episodio se construye narrativamente a partir del acontecimiento narcoterrorista de la voladura del avión de Avianca HK 1803 el 27 de noviembre de 1989, encargado por Pablo Escobar con el objetivo de eliminar a César Gaviria Trujillo, en ese entonces precandidato presidencial, quien abordaría ese vuelo. De acuerdo con el sólido reportaje "La historia que nunca nos contaron", publicado por El Espectador el
} 
En esta cita confluyen dos niveles de acercamiento, uno relacionado con un espacio que también resulta un cuerpo geográfico, y que se lee desde la pobreza: las comunas marginales de Medellín. Esto lo hace dúctil a la manipulación, es un cuerpo desechable, integrante de un ejército desempleado que aguarda en la periferia de la ciudad y que bien ficcionalizó Fernando Vallejo en La virgen de los sicarios. En otra vuelta de tuerca a Rojas Ariza, es un cuerpo en función "de la muerte, de la destrucción" (2016, p. 754).

Pero, además, deviene el resto de una tragedia que lo alcanzó junto a otros 106 cuerpos, desarticulando su humanidad al convertirse en objeto residual entre un "reguero de latas, de sillas, de ropa, de silencio entre el humo negro" (Castaño, 2012, p. 119), y que se hace igual a lo que cierra la tragedia aérea: el residuo, última materialidad, último testimonio tangible de algo que ya no está, en este caso un cuerpo íntegro.

El cuerpo suicidado aparece brevemente, pero define momentos de aprehensión para el cuerpo deprimido de Manuela, de ahí su relevancia. Un joven comisionista de la bolsa se quitó la vida en una coyuntura económica difícil en Argentina, "lo encontraron colgado de la ducha" (Castaño, 2012, p. 174). La viuda y sus hijos ocupan el departamento y aunque la mujer oculta el hecho, la niña se entera. A partir de esto, se inicia un trasvasamiento entre este cuerpo que acabó con su vida y el otro que comienza a alertar con graves señales depresivas, esto se produce a través de un objeto, un "ángel de cristal, [con] las alas recogidas" (174), una suerte de amuleto que quedó abandonado en la escena del suicidio.

El cuerpo depresivo se apodera de esta pieza y la esconde, acosado por el murmullo amenazante de las vecinas que le recuerdan que "en este apartamento hay un alma en pena" (Castaño, 2012, p. 175). Todo se vuelve siniestro para el cuerpo frágil, que se desmorona psicológicamente: una y otra vez imagina al "hombre, colgado de una de sus corbatas, en calzoncillos, un lunes por la

27 de noviembre de 2016, en su Capítulo I, "Un individuo, con el mismo nombre del entonces dueño de Avianca, Julio Santodomingo, dos días antes había comprado dos pasajes para ese vuelo. Uno para él y el otro a nombre de Alberto Prieto. Santodomingo había llegado esa mañana hasta la sala de espera, pero, a último minuto, se abstuvo de abordar el avión. El que sí lo hizo fue el otro pasajero, Alberto Prieto. Un hombre-bomba engañado, o 'suizo' como se decía en el argot del narcotráfico a los suicidas del terrorismo. La misión para la que lo habían reclutado, se diría más tarde, consistió en activar una grabadora escondida en un maletín para registrar la conversación de unos 'sapos' que viajaban adelante suyo, en la fila 14. Prieto activó el obturador de la grabadora que resultó ser una bomba". En Hoffman, Thomas, Correa, Pablo y Silva, Sergio. "Avianca 203, la historia que nunca nos contaron", 26 de noviembre de 2016. https://www.elespectador.com/static_specials/31/avianca-203/index.html (26/03/2018). Sin embargo, no puede dejar de notarse que este reportaje pone en entredicho la hipótesis. 
mañana" (175) y la novia del suicida la persigue para recuperar el ángel de cristal, para ella un regalo de compromiso.

Esta coral de cuerpos que relata alojando saberes entremezclados, se compacta a través de un cuerpo mayor, el de la violencia, pero no está demás subrayar que la novela también devine en sí misma una forma corporal inmensa agujereada por balas y fragmentos de huesos. La manera como Castaño se acerca a la violencia de la narcoguerra es, precisamente, recurriendo al cuerpo como dispositivo simbólico, hablante y "tributario de un estado social" (2002, p. 13), como reveló Le Breton.

\section{El cuerpo mayúsculo de la violencia: como una "jaula de mármol del palacio real"}

La lectura de Rojas Ariza (2016) sobre Michel Foucault y Giorgio Agamben a partir de las tecnologías de dominación del cuerpo ${ }^{9}$, permitirá darle consistencia al vínculo entre los cuerpos dispersos y relatores, superficies de contacto que nombran estados anímicos y trayectos vitales, con ese otro cuerpo mayor, el de la violencia. Concordando con Le Breton en que "El cuerpo es un vector de comprensión de la relación del hombre con el mundo" (2005, p. 18), este vínculo

[...] es la condición necrológica. [...] Significa que la vida moderna apunta, [...] a la consideración del Cuerpo como ente volcado hacia la muerte. Expresión de esto son las múltiples violencias sobre el cuerpo humano [...]. El control y el dominio del cuerpo humano está transformando al mismo (cuerpo) en un territorio - permítase la analogía- del cuerpo como cementerio de disputa en la vida moderna. En consecuencia, lo que estoy diciendo es la mirada sobre el cuerpo que no es solamente un objeto 'inofensivo', sino que trata de un lenguaje todavía más complejo que se relaciona con la violencia de nuestro tiempo (Rojas Ariza, 2016, pp. 753-754).

Al respecto interesa cómo en la novela los cuerpos analizados significan más que una representación particular porque a través de ellos y su inserción directa o indirecta en la muerte, Castaño integra identidades diferentes para elaborar una materialidad mayúscula y contentiva de uno de los enunciados transversales de la contemporaneidad: el de la violencia. Cuerpos separados

\footnotetext{
${ }^{9}$ No obstante tratarse de dos miradas excluyentes, como afirma Rojas Ariza. Por un lado, Foucault inserta la muerte en su perspectiva de relación entre el poder y el cuerpo, mientras que Agamben lo hace desde el concepto de Nuda vida (Rojas Ariza, 2016, p. 753).
} 
que se funden y levantan un "cementerio de disputa" (Rojas Ariza), un cuerpo mayor para mirar el tiempo violento de finales del siglo XX en Colombia.

Complementando estas ideas, el cuerpo posee un "sentido necro-lógico [...]" (Rojas Ariza, 2016, p. 754), por tanto vale argumentar que "el cuerpo de la violencia se convierte en ese gran imaginario, en ese ente, un territorio por explorar, por hallar sus relieves, sus principales rupturas" (754). Esto capitaliza la construcción del cuerpo de la violencia, pues, continuando con el análisis teórico de Rojas Ariza, se trataría de una conformación hermenéutica puesta a disposición de la muerte y la destrucción; por ejemplo, el cuerpo deprimido fusiona una zona del cuerpo de la violencia desde la cual podría comprenderse la secuela directa e individual de la narcoguerra.

Sin embargo, se imponen algunas consideraciones sobre la violencia, no obstante su definición anterior en un pie de página. Debido a su complejidad puede ocurrir que la operación de diferimiento ejecutada a través la literatura se encuentre en idéntico nivel al de la realidad, como si esta se traspasara de manera literal, sin un trabajo de mediación a través del elemento ficcional. Sin desmedro de su valor literario, en la narcoliteratura, ya mencionada, se pueden percibir algunas escenas o sujetos muy apegados al contexto. De ahí que se subraye la diferenciación que marca Kristeva en El texto de la novela (1982):

El relato se presenta como historia; la novela como un discurso (independientemente del hecho que el autor -más o menos consciente- lo reconozca o no como tal). En este sentido constituye una etapa decisiva en el desarrollo de la conciencia crítica del sujeto hablante con relación a su palabra. Terminar la novela en cuanto relato es un problema retórico que consiste en retomar el ideologema cerrado del signo que la ha abierto. Terminar la novela en tanto hecho literario (comprenderla en tanto que discurso=signo) es un problema de práctica social, un problema de texto cultural (73).

Vaciando esta cita en la violencia desde la que se pretende enfocar parte de este artículo y resaltando el giro ficcional que realiza Castaño, las estrategias de representación inquieren por un tratamiento fabulado, de perfil (en la dirección de oblicuidad o contenido implícito, alejada, por ejemplo, de la extensa descripción sociológica de la pobreza en las comunas de Medellín a la que se apegó Vallejo en su obra más emblemática para la crítica), descorriendo los entretelones del "relato [que] se presenta como historia". No se da cuenta del hecho histórico puntual relacionado con la violencia ${ }^{10}$, sino que se novela, tal

${ }^{10}$ En este caso, formando parte de una estética, en general, y de una literatura, en particular, donde "la representación y ficcionalización de la violencia [...] da[n] lugar a nuevas presencias, formas y 
Una "princesa triste, que ha perdido la risa, que ha perdido el color".

Cuerpo y violencia en Cierra los ojos, princesa de José Alejandro Castaño.

como conceptualiza Kristeva: se "problemati[za] retóricamente" hasta hacerlo un "texto cultural".

Esto conduce a Zizěk y la representación simbólica de la violencia, al cómo se plantea o cuánto de alegórico subyace en ella. En el caso de Cierra los ojos, princesa, la violencia se incorpora desde lo no explícito, como posibilidad ficcional. Precisamente, como apuntó el propio Zizěk, "[m]irar al sesgo el problema de la violencia" (2009, p. 12), disponer, como trabajó Castaño, de múltiples cuerpos que, como metáforas, se constituyan frente al lugar violento que han conformado. No proviene del azar la escogencia del cuerpo para suturar la violencia con la ficción, "El cuerpo es la fuente identitaria del hombre; es el lugar y el tiempo en que el mundo se hace carne" (2005, p. 17), otra vuelta de tuerca a Le Breton.

Dentro del contexto colombiano de la novela -el cuerpo enfermo indica hacia otro registro geográfico de la violencia, como se verá-, los cuerpos se hacinan entre la pérdida y la muerte; como se había adelantado, hacen sentido necro-lógico en su inmediatez narrativa, como una larga cronología de corporalidades que funcionan dentro de una maquinaria de muerte, la cual también es de saberes.

Cuerpos que reproducen el funcionamiento celular, moviéndose dispersos y luego agrupándose como una enorme corporalidad violenta. Esto ocurre desde el cuerpo infantil, que más tarde se convertirá en depresivo, escondido en el "pasadizo oscuro donde cabía con amplitud su figura de princesa" (Castaño, 2012, p. 63) para escuchar, como un cuerpo-oreja, los planes siniestros del padre; hasta el cuerpo anónimo y tembloroso que recuerda que "El Doctor les impuso a las gentes de su territorio una obediencia nacida del miedo, un miedo visceral que se acrecentaba con dosis diarias de sangre en las esquinas" (76-77).

Lo fundamental en este cuerpo de la violencia reside en el engranaje perfecto, relator, de los cuerpos individuales abordados anteriormente. Ellos arman la cronología más reveladora alrededor de El Capo y su responsabilidad dentro de la tecnología de muerte y lo delinean como un sujeto portador de una "infamia del conocimiento humano al servicio necro-lógico" (Rojas Ariza, 2016, p. 754), como en la realidad le dijo al periodista Germán Castro Caycedo: "Yo soy todo lo que quise ser: ¡Un bandido!” (2012, p. 192), quien lo entrevistó y dio cuenta de sus vínculos con la guerrilla, la policía, los políticos y la mafia

percepciones de la violencia -en tanto dimensiones y representaciones de un cambio fundamental de la sociedad-, para las cuales el orden anterior resulta insostenible, a la vez que es profundamente transformado" (Mackenbach y Ortiz, 2008, p. 81). 
de la droga, que dejaron un reguero de cuerpos "perforados con taladros en las rodillas, quemados con ácido. [...] atados, con un gesto de miedo, con pavor [...] 'tiroteados'" (189).

Como se planteó, los cuerpos individuales enhebran el cuerpo mayúsculo, colectivo, de la violencia. El cuerpo depresivo manifiesta las derivas traumáticas posteriores al periodo Escobar y es el que más cuenta, el más rico en evidencias, el que evoca el acuerdo del capo con Tuerquita para volar en avión de Avianca, pero también el que ríe con los abusos del padre -"tomó a su hija de la mano y salió a la terraza, donde ordenó suspender al torpe mesero de los pies: el cuerpo en el vacío [...] La niña y el padre decidieron que le vaciaran huevos y salsa por las botas del pantalón. [...] ¡Sí! ¡Sí! ¡Sí!, saltaba la princesa” (Castaño, 2012, pp. 73-74)-, y el que huye con rabia y dolor del siquiátrico cuando observa en la televisión la exhumación de su cuerpo, con "isemejantes huesos, por Dios!" (221), como exclamó una enfermera, pues, cuando lo mataron, se consideraba el "rey Miedo: todo lo que tocaba lo convertía en zozobra"11 (214).

Vale detenerse en la pregunta “¿POR QUÉ COMENZÓ LA GUERRA?” (Castaño, 2012, p. 55. Mayúsculas: en el original). Este enunciado soporta el peso del cuerpo de la violencia, sobre él se cruzan cuerpos espantados, "con las manos amarradas a la espalda, con disparos en el rostro" (Castaño, 2012, p. 76), cuerpos observados por cuerpos asesinos "de sicarios reclutados en los barrios de las periferias [que] vigilaba la ciudad" (76); cuerpos sufridos frente a los cuales a "El Patrón le tenía sin cuidado si la sangre era de ellos o de otros" (76); y cuerpos dinamitados, como los que se mezclaron entre los restos del avión, “¡Dios mío! Qué reguero de destrozos, un avión llenito de personas, así nomás" (104). En su conjunto, como piezas perfectamente acopladas, mueven la maquinaria de muerte y están a su beneficio, alimentándola constantemente, "Cuerpos [...] enfilados, dispuestos a la muerte con otros cuerpos que siguen la misma lógica: obedecen la disciplina de la guerra" (Rojas Ariza, 2016, p. 754), en este caso de la narcoguerra.

Deslizándose hacia otra época y otra geografía, el cuerpo enfermo sobreexpone otra narratología de la violencia, la del nazismo y Alemania. Este cuerpo moribundo introduce una anécdota acerca de la posible sobrevivencia de Adolf Hitler y su esposa Eva Braun, con el sujeto como hijo de la pareja:

[ella] embarazada de pocas semanas, llegaron a bordo de un barco de pesca que los recogió en alta mar a finales de mayo de 1945, después de emerger

\footnotetext{
${ }^{11}$ Esta comparación se contrapone a una anterior en el subtexto de la fábula, cuando los cuerpos de la princesa y su padre se igualaban al del rey Midas pero positivamente: "La princesa también tenía su mismo don: todo lo que tocaba lo convertía en tesoro" (Castaño, 2012, p. 57).
} 
Una "princesa triste, que ha perdido la risa, que ha perdido el color".

Cuerpo y violencia en Cierra los ojos, princesa de José Alejandro Castaño.

de las profundidades del Atlántico en un submarino alemán, [Hitler] llegó sin bigotito, enfundado en un gorro de lana y un abrigo de hule, sin botas militares, cargando un balde con anzuelo sucios de vísceras y un atado de pejerreyes. Sus generales habían hecho correr el rumor de que lo incineraron después de que se suicidó, qué disparate, él, todopoderoso, pegándose un tiro en vez de escapar (Castaño, 2012, p. 185).

El cuerpo narra, “¡Él mismo se lo había contado!” (185), y no solo cambia la historia oficial de cierre de la Segunda Guerra Mundial, la contenida en "los libros de historia" (185), sino también emplaza a Argentina como un nuevo locus del horror. Contar acerca de la sobrevivencia de Hitler es también contar acerca de otro cuerpo, el de la maldad y sus "modales infernales" (Steiner, 2000), pero ahora en un territorio inédito.

El cuerpo enfermo y su condición filial establecen un antes y un después, tanto del acontecimiento belicista europeo como de los eventos terroristas asociados al capo narcotraficante: la llegada a Buenos Aires de la viuda y sus hijos y la compra posterior del hotel del enfermo como bien de resguardo dentro de la circunstancia de clandestinidad impuesta a ellos. Hay una línea de sutura entre la violencia de dos cuerpos colectivos invadidos metafóricamente por cánceres: el de la guerra para la sociedad europea de mediados del siglo XX, y el de la droga para la sociedad colombiana de finales de los años 80 y principiosmediados de los 90; con la de un tercero, individual, invadido literalmente por la enfermedad terminal.

En estos cuerpos se cose la violencia como una materialidad enferma, la cual trata de cerrarse con una pregunta: "Ahora, dígame usted: ¿quién fue su esposo?" (Castaño, 2012, p. 187). Esta interrogante retrotrae al momento cuando la familia recién había arribado a Buenos Aires, específicamente al hotel, y allí, este "hombre flaco, ya viejo, o casi viejo, [con] apariencia enfermiza" (164), observaba los pasatiempos de la mujer y sus hijos y se extrañaba frente a "La niña [que] recogía trozos de escombros y algo les decía en secreto antes de lanzarlos uno por uno contra el agua" (170), anticipo de su grave depresión. La sospecha sobre quiénes pueden ser se articula con la memoria, "El mar es más grande que el pasado más inmenso" (171), ahí coincide un cuerpo que desea conocer con otro que niega la información, por eso el término de la transacción financiera, una vez hospitalizado el primero y a punto de fallecer, se reduce a una petición que busca aclarar la incertidumbre.

También el subtexto de la fábula se integra al cuerpo de la violencia. El reino mágico, protegido y liviano en acontecimientos de fuerza, se cierra 
abruptamente cuando el cuerpo narrador, anónimo, desliza la palabra muerte. Hasta ese momento había dado cuenta de

[...] comidas exquisitas, un palacio hermoso lleno de lujos y riquezas, un bosque de hadas buenas. Los hombres y las mujeres respetaban al rey y a su princesa, que era su hija amada. Vivían felices todos los días, todos los meses, todos los años. La princesa no tenía hermanas ni nadie que se le pareciera. Ella era única, decía el rey (Castaño, 2012, p. 13).

La fábula introduce un sistema narrativo subordinado al texto principal, por esta razón, para forzar un movimiento de tensión con respecto al nivel principal, el autor recurre a una historia mágica, contentiva de elementos fantásticos, "la ilusión de los sentidos" (18) que refería Tzvetan Todorov (1981). El cuerpo deprimido que circula por la narración central muta en un cuerpo alegre, relajado, que "todo lo que tocaba lo convertía en tesoro" (Castaño, 2012, p. 57). No existe una señal de desequilibrio, al contrario, el mundo interior que se contrapone al de afuera derrocha calma y excentricidad, hasta "El rey trajo una jirafa por los aires y le puso el mismo nombre de su princesa" (85).

Esta operación articuladora de dos estratos del relato muestra un cuerpo entre la violencia de la narcoguerra (con la responsabilidad directa del rey) y la torre de marfil creada para un cuerpo del afecto, por ejemplo, el de los familiares en la famosa "Hacienda Nápoles", con su zoológico y sus hectáreas paradisíacas, reinado donde cualquier princesa "lo tenía todo" (Castaño, 2012, p. 13). Como recurso para colisionar estos dos universos, Castaño llena el exterior de "bombas y gente asesinada, [...] policías destripados en las calles, [...] niños mutilados, [...] gente colgada de cabeza" (67) y enfrenta a él, como una delicada pompa de jabón, la dulzura y la protección que viviría una princesa: "¿cómo crees, princesa? [...] No, papi, yo sé que son cocodrilos disfrazados de personas" (67). Así adelanta un diálogo entre el cuerpo infantil, aislado como el de la princesa rubendariana, y el adulto en el futuro, enredado en una telaraña de crímenes y traumas.

Pero, en segundo término, se triza el componente del final feliz de la fábula, la muerte la contamina, ya no es más el reino plácido para la princesa. La burbuja ha explotado, el afuera brutal la resquebrajó, y el cuerpo de Manuela deberá conformarse con el sueño como único lugar de encuentro con el rey; además de deprimirlo en la adultez, soñarlo lo recobrará en una infancia inconclusa que ella no desea terminar y en la cual "jugarían, comerían helado, nadarían en el agua de las nubes, montarían en su unicornio" (Castaño, 2012, p. 219). 
En estas rupturas se potencia la condición necro-lógica de la muerte que conlleva a "la comprensión de la Téchne moderna al servicio de la muerte, de la destrucción" (Rojas Ariza, 2016, p. 754), en el sentido de poner en evidencia narrativamente el espacio de horror y muerte originado por las actuaciones del gobierno colombiano contra los cárteles, con el apoyo del paramilitarismo y organizaciones norteamericanas como la DEA, y también desde los cárteles hacia este y sus aliados.

Retomando a Rojas Ariza, "El paso de la violencia del cuerpo al cuerpo de la violencia es la forma de ver cómo se ha fusionado el conocimiento humano al servicio de la muerte" (2016: 754). Al final de la novela, la fábula funde engañosamente los cuerpos del rey y la princesa frente a un espejo "donde tenían el mismo reflejo" (Castaño, 2012, p. 219), el presente se ha instalado: él, asesinado, y ella huyendo y obligada a cambiar su identidad. La muerte como tecnología que atraviesa el cuerpo falsifica sus contornos e instala su más preciado dispositivo: la violencia.

\section{4. "La pobre princesa [...] quiere ser golondrina, quiere ser mariposa". A manera de epílogo}

Para Le Breton el cuerpo es un "mundo de significaciones y valores, de connivencia y comunicación, que no cesa de abrirse frente al andar del hombre" (2005: 18). En esta dirección, se puede pensar este dispositivo como una obraen-construcción, que permite operaciones de montaje y desmontaje desde las cuales saber sobre el individuo y el mundo por el que transita, marcado en la contemporaneidad por la violencia y sus tecnologías de afianzamiento transversal en la sociedad, entre ellas la muerte.

Como aporte de este artículo, se puede afirmar que la novela de Castaño elabora ficcionalmente múltiples cuerpos que (se)relatan a través de sus manifestaciones depresivas, exhumadas, temerosas, abyectas, enfermas, destrozadas y borradas por el suicidio, para luego entrelazarlos y conseguir el cuerpo mayor de la violencia, el cual este autor construye como si se tratara de un manuscrito de piel sobre el que pueden tatuarse los entresijos de un periodo convulso de la reciente historia colombiana.

Esta novela semeja un enorme depósito escritural de cuerpos narrando intimidades, miedos y traumas derivados del sentido necro-lógico de la muerte, por la guerra a su servicio (Rojas Ariza, 2016). Todos son cuerpos desechados y rotos donde no caben fábulas de reinos y unicornios ni tampoco princesas depresivas a las que la violencia cerró sus ojos inocentes para siempre. 


\section{Referencias}

Castaño, José Alejandro (2012). Cierra los ojos, princesa. Bogotá: Ícono.

Castro Caycedo, Germán (2012). Operación Pablo Escobar. Bogotá: Planeta.

Fritz, Vivian (2005). "Introducción". En D. Le Breton (Ed.), Cuerpo sensible (pp.17-20.) Santiago de Chile: Ediciones Metales Pesados.

García Casanova, Juan F. et al. (eds.) (2014). El cuerpo y sus expresiones. Granada: Universidad de Granada.

Kristeva, Julia (1982). El texto de la novela. Buenos Aires: Lumen.

Kristeva, Julia (1989). Poderes de la perversión. México: Siglo Veintiuno Editores.

Le Breton, David (2002). Antropología del cuerpo y la modernidad. Buenos Aires: Nueva Visión.

Le Breton, David (2005). Cuerpo sensible. Santiago de Chile: Ediciones Metales Pesados.

Mackenbach, Werner y Ortiz Wallner, Alexandra (2008). "(De) formaciones: violencia y narrativa en Centroamérica”. Revista Iberoamericana, 32, pp. 81-97.

Nancy, Jean-Luc. (2010). 58 indicios sobre el cuerpo, Extensión del alma. Buenos Aires: La Cebra.

Rojas Ariza, Yuber H. (2016). "Cuerpo de una violencia infame. Algunas apreciaciones para una hermenéutica de la violencia". Daimon. Revista Internacional de Filosofía, 5, pp. 747-755.

Salazar, Alonso (2000). "Hacia una estrategia de reconstrucción cultural". En S. Rotker (Ed.), Ciudadanías del miedo (pp. 169-181). Caracas: Nueva Sociedad. 
Steiner, George (2000). Lenguaje y silencio. Ensayos sobre la literatura, el lenguaje y lo inhumano. Barcelona: Gedisa.

Todorov, Tzvetan (1981). Introducción a la literatura fantástica. México: PREMIA editora de libros.

Zizěk, Slajov (2009). Sobre la violencia. Seis reflexiones marginales. Barcelona: Paidós. 